\title{
Guffuf Ainulf.
}

$3^{\text {weiter }} \mathfrak{B a n b}$. 



\section{Gultaf Adolf.}

Bolt

(․) $\mathfrak{D} \mathfrak{x} \mathfrak{y} \mathfrak{i} \mathfrak{n}$.

$Z_{\text {weiter }} \mathfrak{B a n d}$.

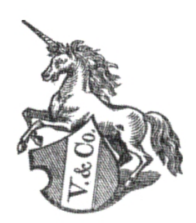

Tripzig,

Berlag von $\mathfrak{B e i t} \&$ Eomp.

1870. 
